\title{
Hip fracture care in Manitoba, Canada and New York State, United States: an analysis of administrative data
}

\author{
Peter Cram MD MBA, Lisa M. Lix PhD, Eric Bohm MD MSc, Lin Yan MSc, Leslie Roos PhD, \\ John Matelski MSc, Rajiv Gandhi MD MSc, Bruce Landon MD MBA, William D. Leslie MD MSc
}

\section{Abstract}

Background: Nearly 30 years ago, a series of studies showed increased hip fracture mortality in Manitoba compared to the United States, but these data have not been updated. Our objective was to compare the organization of hip fracture care and short-term outcomes in Manitoba and New York State using contemporary data.

Methods: This was a retrospective cohort study of administrative data for all adults aged 50 years or more admitted to hospital with hip fracture between Jan. 1, 2011, and Oct. 31, 2013 in Manitoba and New York State. We compared the 2 jurisdictions with respect to: 1) the proportion of hospitals treating hip fracture and annual hip fracture volume, 2) hospital length of stay, 3) death and 4) hospital readmission. We used descriptive statistics, univariate methods and regression models to compare differences in care between jurisdictions.

Results: We identified 2845 patients (mean age 82.2 yr, 2061 women [72.4\%]) with hip fracture in Manitoba and 31524 patients (mean age $81.9 \mathrm{yr}, 22973$ women [72.9\%]) with hip fracture in New York. A smaller proportion of hospitals in Manitoba than in New York treated hip fracture $(7 / 30[23 \%]$ v. $180 / 239[75.3 \%])(p<0.001)$; the mean annual hospital hip fracture volume was higher in Manitoba (140.0) than in New York (68.9), but the difference did not reach statistical significance $(p=0.2)$. For patients with femoral neck fractures, the median hospital length of stay was longer in Manitoba than in New York (13 d v. $7 \mathrm{~d}$ ). The rate of death within 7 days of admission was similar in Manitoba and New York (1.3\% v. 2.0\%, $p=0.07$ ), although the rate of in-hospital death was higher in Manitoba $(5.7 \%$ v. $3.5 \%, p<0.001)$. Readmission within 30 days of discharge was less frequent in Manitoba than in New York $(9.8 \%$ v. $12.0 \%, p=0.02)$. Results were similar for patients with intertrochanteric fractures.

Interpretation: Poor short-term outcomes for patients with hip fracture in Manitoba that were documented in the 1980s seem to have been eliminated. Our results should provide optimism that reengineering of clinical care can produce substantive improvements in quality.

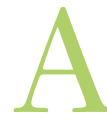

bout 30000 Canadians and 200000 Americans experience hip fracture annually. ${ }^{1,2}$ One-year mortality rates for older adults with hip fracture are $20 \%-$ $25 \%,{ }^{3-5}$ and about $25 \%$ of survivors are unable to live independently 1 year after their fracture. ${ }^{6}$

International population-based comparative studies are important for benchmarking purposes, ${ }^{7}$ but international comparisons of hip fracture are limited. ${ }^{8-10}$ A 1990 study by Roos and colleagues ${ }^{9}$ showed higher short-term mortality in Manitoba than in New England for patients who underwent hip fracture repair. A series of follow-up studies in which data from the 1980s and 1990s were used confirmed higher mortality rates in Manitoba than in several US jurisdictions and showed that delays in time to surgery were not the major driver of these differences. ${ }^{8,11}$ As a consequence of these quality concerns, hip fracture care in Manitoba has undergone substantial transformation over the past 2 decades. Key aspects of this transformation have included regionalization of hip fracture care to a small number of high-volume centres ${ }^{12}$ and streamlining patient triage and transfer to minimize surgical delays. ${ }^{13}$ This work required extensive cooperation among government, hospitals and

\section{Competing interests: None declared.}

This article has been peer reviewed.

Correspondence to: Peter Cram, peter.cram@uhn.ca

CMAJ Open 2019. DOI:10.9778/cmajo.20180126 
physicians. Data from the Canadian Institute for Health Information over the past decade have documented success in achieving expedited surgery, with about $90 \%$ of patients in Manitoba now receiving surgery within 48 hours. ${ }^{14}$ However, it is unclear whether these efforts have reduced the previously described gap.

Manitoba and New York State provide an interesting contrast. Residents of Manitoba are virtually all (99\%) insured through the provincial health insurance program; hip fracture surgery is concentrated in a small number of hospitals through governmental regulation. ${ }^{15}$ In contrast, New York residents are insured by a patchwork of public (Medicare, Medicaid) and private insurance plans, with $7 \%$ of residents lacking health insurance altogether; surgical repair of hip fracture is loosely regulated. ${ }^{16,17}$ The current work was motivated by our interest in assessing whether the clinical transformation of Manitoba hip fracture care has reduced or eliminated the gap in outcomes that had been observed nearly 30 years ago. ${ }^{9,11,18}$ We used administrative data from Manitoba and New York State to compare differences in 1) operative management of hip fracture, 2) in-hospital mortality and 3) measures of efficiency including hospital length of stay and 30-day readmission rates.

\section{Methods}

For both Manitoba (geographic area $650000 \mathrm{~km}^{2}$, population 1.2 million $^{19}$ ) and New York (geographic area $141000 \mathrm{~km}^{2}$, population 20.0 million $^{20}$ ), we used administrative data to identify all adults aged 50 years or more admitted to hospital with hip fracture between Jan. 1, 2011, and Oct. 31, 2013.

\section{Manitoba data}

We accessed Manitoba provincial insurance data through the Manitoba Centre for Health Policy at the University of Manitoba. Manitoba data have been extensively audited, validated and used for prior health services research studies. ${ }^{21}$ The Population Research Data Repository contains multiple Manitoba Centre for Health Policy administrative health databases, which include information about virtually all hospital admissions, physician visits and postacute care paid for by the provincial health insurance plan. Additional files include the population registry, which captures information on dates of health insurance coverage (including cessation of coverage owing to death and out-of-province migration), demographic characteristics and geographic information. Facility information includes teaching status and bed counts for all acute care facilities. For each hospital admission, available data include demographic characteristics (age, sex), comorbid conditions captured with the use of enhanced Canadian version of the International Statistical Classification of Diseases and Related Health Problems, 10th revision (ICD-10-CA) codes, procedures captured with Canadian Classification of Health Intervention codes, admission source (emergency department, transfer from another acute care hospital, other), admission and discharge dates, and discharge disposition (e.g., died, long- term care). A unique patient identifier allows for creation of longitudinal linkages for tracking patient readmissions. We used Quan and colleagues'22 adaptation of the Elixhauser comorbidity coding system for capturing comorbidity present in the index hospital admission records.

\section{New York data}

We obtained New York data from the New York State Inpatient Database (SID), provided by the Agency for Healthcare Research and Quality. ${ }^{23,24}$ Briefly, the New York SID contains administrative data for all patients admitted to acute care hospitals, excluding small numbers of psychiatric and Veterans hospitals. The SID data undergo numerous quality checks and extensive processing by the Agency for Healthcare Research and Quality before release ${ }^{23}$ and have been used extensively in prior research. ${ }^{25,26}$ Additional details are available on the agency's SID website (www.hcup-us.ahrq.gov/sidoverview.jsp). Key elements in the SID relevant to our study included patient demographic characteristics, primary and secondary diagnosis and procedures (coded with the clinical modification of the International Classification of Diseases, 9th revision [ICD9-CM] codes), admission source (emergency department, transfer from another acute care hospital, other), admission and discharge dates, and discharge disposition (e.g., died in hospital, home, postacute care). We evaluated most comorbid conditions using algorithms developed by Elixhauser and colleagues $^{27}$ and identified dementia by means of the DeyoCharlson methodology. ${ }^{22} \mathrm{~A}$ unique patient identifier within the New York SID allows for following patients after discharge for purposes of tracking hospital readmissions and interhospital transfers, but data on out-of-hospital death are not available.

\section{Cohort generation}

We identified all patients admitted to hospital with a primary diagnosis of femoral neck fracture or intertrochanteric fracture using ICD-10-CA codes S72.0, S72.1 in Manitoba and ICD-9-CM codes 820.0X and 820.21 in New York by means of established methods. ${ }^{15,28}$ For patients with multiple admissions for hip fracture, we selected the first admission within our proscribed time window.

We excluded patients with a hip fracture admission during the 90-day period before the index admission because of concern that the index admission might represent a readmission (rather than a new fracture). We excluded patients admitted after Oct. 31, 2013 to allow for a full 60 days following the admission to follow up on study outcomes. We excluded patients with multiple fractures or evidence of trauma, applying previously used coding schemes, ${ }^{15}$ because of our interest in identifying a cohort of patients with isolated hip fractures (codes available by request). We used available patient identifiers to track patients transferred between hospitals to create a single longitudinal record for the entire episode of care. We also excluded patients with a length of stay for the entire episode of care of 1 day or less, as such a short stay would not be clinically consistent with hip fracture. 


\section{Outcomes of interest}

Outcomes included mean annual volume of hip fracture repair by hospital, proportion of Manitoba and New York hospitals performing hip fracture surgery, hospital length of stay, death within 7 days of hip fracture admission as well as the overall in-hospital mortality rate, readmission within 30 days of discharge and discharge disposition (categorized as rehabilitation/long-term care v. home) among patients who survived the hospital stay.

\section{Statistical analysis}

We compared demographic characteristics and presence of key comorbid conditions among patients admitted to hospital with isolated hip fracture in Manitoba and New York using univariate tests (e.g., independent sample $t$ tests, $\chi^{2}$ tests of independence). We used univariate tests to compare admission source, whether the patient was transferred between hospitals before undergoing surgery and hip fracture type (classified as femoral neck or intertrochanteric). We calculated age- and sex-standardized hip fracture rates (hip fractures per 10000 adults aged $\geq 50 \mathrm{yr}$ ) using a direct standardization approach. ${ }^{29}$ The numerator was the number of fractures in the jurisdiction during the study period, and the denominator was the number of adults aged 50 years or more in the jurisdiction in 2013, derived from census data.

We also used univariate tests to compare Manitoba and New York hospitals with respect to proportion of all acute care hospitals performing surgical hip fracture repair, mean hip fracture volume, mean number of hospital beds and, among those performing surgical repair, the number that were major teaching hospitals.

To compare outcomes between Manitoba and New York, we stratified by hip fracture subtype (femoral neck or intertrochanteric fracture) since treatment typically differs depending on fracture subtype. Within the 2 fracture subtypes, we compared 1) the proportion of patients who received each type of treatment (total hip arthroplasty, hemiarthroplasty, internal fixation and nonoperative management), 2) the median hospital length of stay and interquartile range (IQR), and proportion of patients with a longer stay (defined as $\geq 30 \mathrm{~d}$ ), 3) death within 7 days of admission and overall inhospital mortality, 4) hospital readmission within 30 days of discharge among patients discharged alive and 5) discharge disposition (categorized as rehabilitation/long-term care v. home) for patients discharged alive. We also examined outcomes in 2 distinct patient subgroups. Subgroup 1 consisted of a homogeneous group of patients who met the following criteria: hospital admission from the emergency department, not transferred from another acute care hospital and length of stay for the hip fracture episode of care 90 days or less. Subgroup 2 consisted of patients who did not meet these criteria and thus typically underwent interhospital transfer and/or had a longer hospital stay.

We used logistic regression models for the analysis of binary outcomes (e.g., in-hospital death) and generalized linear models for the analysis of continuous outcomes (e.g., hospital length of stay). These models were fit separately to the data from Manitoba and New York. For each outcome specified above, we ran both unadjusted and adjusted models separately for the femoral neck and intertrochanteric fracture groups. Our adjusted models included the predictors of patient demographic characteristics, comorbid conditions, hospital hip fracture volume and hospital length of stay (length of stay was excluded from the models in which length of stay was the outcome). We centred continuous predictors (i.e., hospital hip fracture volume and age) at the mean for easier interpretation of model intercepts. We calculated adjusted (i.e., conditional) predictions of each outcome for female patients at mean age, mean hospital hip fractures volume and without any comorbid conditions listed in the model. Finally, we compared unadjusted and adjusted predictions between Manitoba and New York using a $z$ score (calculated as $z=d / S E[d])$, where $d$ is the difference of 2 estimates (Manitoba and New York) and has standard error SE(d), which is calculated as the square root of the sum of the squares of the separate SEs. We compared the value of $z$ to the appropriate percentile from the standard normal distribution to test the null hypothesis that the difference, $\mathrm{d}$, was 0 .

All analyses were performed with SAS version 9.4 (SAS Institute) or R version 3.4 (R Foundation for Statistical Computing) software.

\section{Ethics approval}

This work was approved by the research ethics boards at the University of Manitoba and University Health Network. Data access was granted by the Health Information Privacy Committee in Manitoba.

\section{Results}

Our study cohort consisted of 2845 patients in Manitoba and 31524 patients in New York who experienced hip fracture between Jan. 1, 2011, and Oct. 31, 2013. Patient demographic characteristics (age, sex) were similar across jurisdictions (Table 1). The prevalence of most comorbid conditions was significantly lower among patients in Manitoba than among those in New York (Table 1). Patients in Manitoba were significantly less likely to be admitted from the emergency department than patients in New York (2309 [81.2\%] v. 28055 [89.0\%], $p<0.001)$, whereas patients in Manitoba were more likely to be admitted after transfer from another hospital (336 [11.8\%] v. 1410 [4.5\%], $p<0.001)$ (Table 1). The annual hip fracture rate was significantly higher in Manitoba than in New York (22.7 v. 16.7 per 10000 population, $p<0.001$ ) (Supplementary Table S1, Appendix 1, available at www.cmajopen.ca/content/7/1/E55/suppl/DC1). Compared to hip fractures in New York, hip fractures in Manitoba were more likely to be coded as femoral neck fractures and less likely to be coded as intertrochanteric $(p<0.001)$. A significantly lower proportion of hospitals in Manitoba than in New York performed hip fracture repair (7/30 [23\%] v. 180/239 [75.3\%], $p<0.001$ ) (Table 2). Annual hospital hip fracture volumes were higher in Manitoba than in New York (mean 140.0 v. 68.9$)$, but not significantly so $(p=0.2)$. 
Table 1: Characteristics of patients admitted to hospital with hip fracture in Manitoba and New York State, 2011-2013

\begin{tabular}{|c|c|c|c|}
\hline \multirow[b]{2}{*}{ Characteristic } & \multicolumn{2}{|c|}{ No. $(\%)$ of patients* } & \multirow[b]{2}{*}{$p$ value } \\
\hline & $\begin{array}{l}\text { Manitoba } \\
n=2845\end{array}$ & $\begin{array}{c}\text { New York } \\
n=31524\end{array}$ & \\
\hline \multicolumn{4}{|l|}{ Demographic } \\
\hline Age, yr, mean \pm SD & $82.2 \pm 10.0$ & $81.9 \pm 10.3$ & 0.1 \\
\hline Female sex & 2061 (72.4) & 22973 (72.9) & 0.6 \\
\hline \multicolumn{4}{|c|}{ Prevalence of selected comorbid conditions } \\
\hline $\begin{array}{l}\text { Congestive heart } \\
\text { failure }\end{array}$ & $280(9.8)$ & $5696(18.1)$ & $<0.001$ \\
\hline Depression & $81(2.8)$ & $4564(14.5)$ & $<0.001$ \\
\hline $\begin{array}{l}\text { Uncomplicated } \\
\text { hypertension }\end{array}$ & $1564(55.0)$ & $17725(56.2)$ & 0.2 \\
\hline $\begin{array}{l}\text { Diabetes with } \\
\text { complications }\end{array}$ & $287(10.1)$ & $858(2.7)$ & $<0.001$ \\
\hline $\begin{array}{l}\text { Chronic obstructive } \\
\text { pulmonary disease }\end{array}$ & $303(10.6)$ & $7251(23.0)$ & $<0.001$ \\
\hline Renal failure & $102(3.6)$ & $4858(15.4)$ & $<0.001$ \\
\hline Dementia & $717(25.2)$ & $1103(3.5)$ & $<0.001$ \\
\hline \multicolumn{4}{|l|}{ Admission source } \\
\hline $\begin{array}{l}\text { Emergency } \\
\text { department }\end{array}$ & $2309(81.2)$ & $28055(89.0)$ & $<0.001$ \\
\hline Other† & $536(18.8)$ & $3469(11.0)$ & $<0.001$ \\
\hline $\begin{array}{l}\text { Transfer from another } \\
\text { acute care hospital } \\
\text { before surgery }\end{array}$ & $336(11.8)$ & $1410(4.5)$ & $<0.001$ \\
\hline \multicolumn{4}{|l|}{ Fracture type } \\
\hline Femoral neck & $1500(52.7)$ & $11264(35.7)$ & $<0.001$ \\
\hline Intertrochanteric & $1345(47.3)$ & 20260 (64.3) & $<0.001$ \\
\hline \multicolumn{4}{|c|}{$\begin{array}{l}\text { Note: } \mathrm{SD}=\text { standard deviation. } \\
\text { "Except where noted otherwise. } \\
\text { †Admission from outpatient clinics, ambulatory surgery centres or unknown } \\
\text { sources. }\end{array}$} \\
\hline
\end{tabular}

Table 2: Characteristics of hospitals in the 2 jurisdictions

\begin{tabular}{|lccc|}
\hline Characteristic & $\begin{array}{c}\text { Manitoba } \\
n=30\end{array}$ & $\begin{array}{c}\text { New York } \\
n=239\end{array}$ & $p$ value \\
\hline $\begin{array}{l}\text { No. (\%) performing hip } \\
\text { fracture surgery }\end{array}$ & $7(23)$ & $180(75.3)$ & $<0.001$ \\
\hline $\begin{array}{l}\text { Annual hip fracture } \\
\text { volume, mean } \pm \text { SD }\end{array}$ & $140.0 \pm 127$ & $68.9 \pm 61.9$ & 0.2 \\
\hline $\begin{array}{l}\text { Annual hip fracture } \\
\text { volume, median (IQR) }\end{array}$ & $107(68-233)$ & $52(26-96)$ & NA \\
\hline $\begin{array}{l}\text { No. of beds, mean } \\
\pm \text { SD }\end{array}$ & $271 \pm 230^{*}$ & $347.0 \pm 297.4 \dagger$ & 0.4 \\
\hline $\begin{array}{l}\text { No. (\%) major teaching } \\
\text { 2 (29) }\end{array}$ & $27(15.9) \dagger$ & 0.6 \\
\hline $\begin{array}{l}\text { Note: IQR = interquartile range, NA = not applicable, SD }=\text { standard deviation. } \\
\text { *Pertains to the 7 Manitoba hospitals performing hip fracture surgery. } \\
\text { tPertains to the 170 New York hospitals performing hip fracture surgery that could } \\
\text { be linked to the American Hospital Association database. }\end{array}$ \\
\hline
\end{tabular}

In analyses focusing on patients with femoral neck fractures, those in Manitoba were significantly less likely to receive nonoperative management than those in New York (66 [4.4\%] v. 939 [8.3\%], $p<0.001$ ) (Table 3). The use of hemiarthroplasty was significantly higher in Manitoba (895 [59.7\%] v. 6154 [54.6\%], $p<0.001)$. Differences in surgical management for patients with intertrochanteric fractures were minimal (Table 3).

\section{Outcomes}

Among patients with femoral neck fractures, in unadjusted analyses, the median hospital length of stay in Manitoba was significantly greater than that in New York (13 d v. 7 d) (Table 3). The unadjusted rate of death within 7 days of admission was $1.3 \%$ in Manitoba, compared to $2.0 \%$ in New York $(p=0.07)$, but in-hospital mortality was significantly higher in Manitoba than in New York (85 [5.7\%] v. 392 [3.5\%], $p<0.001)$, consistent with the longer length of stay in the former (Table 3). The rate of hospital readmission within 30 days of discharge was significantly lower in Manitoba than in New York (139/1415 [9.8\%] v. 1307 [12.0\%], $p=0.02)$, and a significantly lower proportion of patients in Manitoba than in New York were discharged to rehabilitation or longterm care (755 [53.4\%] v. 8648 [79.5\%], $p<0.001)$. Results for patients with intertrochanteric fractures were generally similar (Table 3).

Many of the Manitoba-New York differences were reduced in subgroup 1 (patients who were admitted from the emergency department and did not undergo interhospital transfer) and increased in subgroup 2 (Appendix 1). For example, among patients with femoral neck fractures, in subgroup 1, the median hospital length of stay was 5 days longer in Manitoba than in New York (12 d v. $7 \mathrm{~d})$, and in subgroup 2, the median length of stay was 10 days longer in Manitoba than in New York (17 d v. 7 d). In adjusted analyses, patients in Manitoba had longer hospital length of stay than those in New York but similar rates of in-hospital death and 30-day readmission (Table 4).

\section{Interpretation}

In this analysis of contemporary data for patients admitted to hospital with hip fracture, we found that outcomes in Manitoba were similar to those in New York State. In the context of older studies showing inferior hip fracture outcomes in Manitoba relative to the US, 8,9 our results suggest that Manitoba's well-documented transformation of hip fracture care has had tangible impact. ${ }^{12,13}$ Several of our findings warrant elaboration. First, we should note that the age and sex of patients with hip fracture were similar in Manitoba and New York, whereas the incidence of most comorbid conditions was significantly lower in Manitoba. The finding of similar age and sex between the jurisdictions has face validity. However, our findings of $85 \%$ higher prevalence of congestive heart failure in New York but more than $600 \%$ higher prevalence of dementia in Manitoba seem biologically implausible. A likely explanation is that age and sex are relatively simple to 
Table 3: Surgical treatment and unadjusted outcomes by fracture type

\begin{tabular}{|c|c|c|c|c|c|c|}
\hline \multirow[b]{2}{*}{ Treatment/outcome } & \multicolumn{2}{|c|}{ Femoral neck; no. (\%) of patients* } & \multirow[b]{2}{*}{$p$ value } & \multicolumn{2}{|c|}{$\begin{array}{l}\text { Intertrochanteric; no. (\%) } \\
\text { of patients* }\end{array}$} & \multirow[b]{2}{*}{$p$ value } \\
\hline & $\begin{array}{l}\text { Manitoba } \\
n=1500\end{array}$ & $\begin{array}{c}\text { New York } \\
n=11264\end{array}$ & & $\begin{array}{l}\text { Manitoba } \\
n=1345\end{array}$ & $\begin{array}{c}\text { New York } \\
n=20260\end{array}$ & \\
\hline \multicolumn{7}{|l|}{ Procedure } \\
\hline Total hip arthroplasty & $122(8.1)$ & $928(8.2)$ & 0.9 & $9(0.7)$ & $141(0.7)$ & 1.00 \\
\hline Hemiarthroplasty & $895(59.7)$ & $6154(54.6)$ & $<0.001$ & $12(0.9)$ & 379 (1.9) & 0.01 \\
\hline Internal fixation & $417(27.8)$ & $3243(28.8)$ & 0.4 & $1239(92.1)$ & $18605(91.8)$ & 0.7 \\
\hline Nonoperative & $66(4.4)$ & $939(8.3)$ & $<0.001$ & $85(6.3)$ & $1135(5.6)$ & 0.3 \\
\hline $\begin{array}{l}\text { Hospital length of stay, median } \\
\text { (IQR) }\end{array}$ & $13(8-24)$ & $7(5-12)$ & NA & $13(8-27)$ & $7(5-12)$ & NA \\
\hline Hospital length of stay $\geq 30 \mathrm{~d}$ & $296(19.7)$ & $360(3.2)$ & $<0.001$ & $318(23.6)$ & $612(3.0)$ & $<0.001$ \\
\hline Death within $7 \mathrm{~d}$ of admission & $20(1.3)$ & $227(2.0)$ & 0.07 & $28(2.1)$ & $429(2.1)$ & 1.00 \\
\hline In-hospital death & $85(5.7)$ & $392(3.5)$ & $<0.001$ & $96(7.1)$ & $761(3.8)$ & $<0.001$ \\
\hline $\begin{array}{l}\text { Readmission within } 30 \mathrm{~d} \text { of } \\
\text { discharge†f }\end{array}$ & $139(9.8)$ & $1307(12.0)$ & 0.02 & $117(9.4)$ & 2273 (11.2) & 0.02 \\
\hline $\begin{array}{l}\text { Discharge to rehabilitation or } \\
\text { long-term care†‡ }\end{array}$ & 755 (53.4) & 8648 (79.5) & $<0.001$ & 768 (61.5) & $15569(79.8)$ & $<0.001$ \\
\hline \multicolumn{7}{|c|}{$\begin{array}{l}\text { Note: IQR = interquartile range. } \\
\text { `Except where noted otherwise. } \\
\text { †Denominator for femoral neck fractures in Manitoba consisted of all patients who survived to discharge: } 1415 \text { for all patients, } 1051 \text { for patients who did not undergo transfer } \\
\text { and } 364 \text { for patients who underwent transfer. } \\
\text { fDenominator for intertrochanteric fractures in Manitoba consisted of all patients who survived to discharge: } 1249 \text { for all patients, } 988 \text { for patients who did not undergo } \\
\text { transfer and } 261 \text { for patients who underwent transfer. }\end{array}$} \\
\hline
\end{tabular}

\begin{tabular}{|c|c|c|c|c|}
\hline \multirow[b]{2}{*}{ Outcome } & \multicolumn{2}{|c|}{$\begin{array}{l}\text { Femoral neck; point estimate } \\
\qquad(95 \% \mathrm{Cl}), \%\end{array}$} & \multicolumn{2}{|c|}{$\begin{array}{l}\text { Intertrochanteric; point estimate } \\
(95 \% \mathrm{Cl}), \%\end{array}$} \\
\hline & Manitoba & New York & Manitoba & New York \\
\hline Hospital length of stay & 32.7 (27.4-38.0) & $9.4(8.9-9.9)$ & $39.3(33.9-44.8)$ & $9.5(9.3-9.8)$ \\
\hline $\begin{array}{l}\text { Hospital length of stay } \\
>30 \mathrm{~d}\end{array}$ & $28.2(23.1-34.0)$ & $2.2(1.8-2.7)$ & $32.7(26.9-39.1)$ & $2.3(1.9-2.7)$ \\
\hline In-hospital death & $2.8(1.3-5.8)$ & $2.0(1.7-2.4)$ & $4.3(2.2-8.2)$ & $3.4(3.0-3.9)$ \\
\hline $\begin{array}{l}\text { Readmission within } 30 \mathrm{~d} \\
\text { of discharge }\end{array}$ & $8.2(4.9-13.2)$ & $9.2(8.3-10.3)$ & $7.7(4.5-13.0)$ & $9.6(8.90-10.4)$ \\
\hline \multicolumn{5}{|c|}{$\begin{array}{l}\text { Note: } \mathrm{Cl}=\text { confidence interval. } \\
\text { *Adjusted for demographic characteristics, comorbidities (congestive heart failure, coronary artery disease, hypertension, diabetes, } \\
\text { chronic obstructive pulmonary disease and renal failure), hospital hip fracture volume and hospital length of stay. }\end{array}$} \\
\hline
\end{tabular}

measure and are probably accurate in both jurisdictions. Alternatively, coding of comorbidities is complex and likely depends on factors such as electronic health record adoption, training of coders and billers, and financial incentives by payers to doctors and hospitals to code comorbid conditions, ${ }^{30-32}$ which likely drove the differences we observed. We view the similar age and sex distribution in Manitoba and New York as evidence that we are comparing "apples to apples," even if comorbidities differ widely.

Our finding that only $23 \%$ of Manitoba hospitals perform hip fracture surgery, compared to $75 \%$ in New York, reflects consolidation of hip fracture care in Manitoba, whereas New York (like most of the US) takes a laissez faire approach, allowing most hospitals to perform surgical repair without undue oversight. ${ }^{33,34}$ The high degree of regionalization of hip fracture care in Manitoba has both advantages and drawbacks. ${ }^{12}$ The primary advantage is substantially higher hospital volumes. Importantly, although some studies suggest that higher hospital (and surgeon) volumes are associated with improved outcomes (so-called "practice makes perfect), 35,36 other studies support a selective referral process whereby higher-quality hospitals "obtain" higher volumes over 
time. ${ }^{37,38}$ Mean hospital hip fracture volume was substantially higher in Manitoba than in New York (140 v. 69 patients per year); although not statistically significant because of the small sample, these differences are clinically noteworthy. Drawbacks may include an increased need to transfer patients to regional centres far from home., $4,39,40$

It is important to consider the prolonged hospital length of stay we observed in Manitoba. More specifically, median length of stay was 13 days in Manitoba versus 7 days in New York, and about 20\% of Manitoba patients had a length of stay of 30 days or more, compared to $3 \%$ in New York. Although delays in surgery in Manitoba have now been thoroughly addressed, we know from other studies that patients in Manitoba and elsewhere in Canada often have discharge delayed by a chronic lack of rehabilitation or long-term care beds. $^{41,42}$ Delays in discharge can be detrimental to patients who need physical therapy and rehabilitation and to overcrowded hospitals in need of beds. ${ }^{43}$ These delays, however, may also explain lower rates of readmission and lower rates of discharge to rehabilitation or long-term care facilities because patients are given a much longer time to recover in hospital.

We found similar rates of in-hospital death within 7 days of admission in Manitoba and New York but higher inhospital mortality in Manitoba. Similar rates of death within 7 days of admission should be reassuring; alternatively, higher in-hospital mortality likely reflects longer length of stay in Manitoba which provides greater opportunity to observe inhospital deaths. ${ }^{11}$ Our results suggest that the systematic redesign of hip fracture care across Manitoba ${ }^{13}$ has resulted in substantial improvements and that deficits observed in prior studies have been eliminated. , $^{8,9,11}$

Second, it is important to mention the differences between Manitoba and New York and how the 2 jurisdictions may be representative of health care in their respective countries. The differences between the Canadian and US health care systems have been described extensively. ${ }^{44-46}$ Canada spends roughly $11 \%$ of its gross domestic product on health care, whereas the US spends about $18 \% .{ }^{47}$ Canadian health care has been praised for providing equal access to all legal residents without copayments or private sector competition, but criticized for problems with access and wait times. ${ }^{48,49}$ In contrast, the US has been praised for outstanding quality for those with an ability to pay, but widespread disparities exist in care available to rich and poor. ${ }^{50,51}$ The province of Manitoba is largely rural, and about $70 \%$ of the population is of European/white ethnicity, with the largest minority being the Indigenous population; the province could be considered representative of much of Canada's rural centre. ${ }^{52,53}$ New York is smaller and more densely populated than Manitoba, and about $70 \%$ of the population is of European/white ethnicity, with the largest minority being the African-American/black population. ${ }^{20}$ The Manitoba Health Insurance Plan (www.gov.mb.ca/health/ mhsip/) provides insurance to all legal residents (about $99 \%$ of the population) and oversees delivery of health care services across the province. In contrast, as in the entire US, residents of New York obtain insurance from a mix of public (Medicare, Medicaid) and private insurers. Even with the passage of the Affordable Care Act, about 7\% of New Yorkers lack health insurance, and copayments are often quite high. ${ }^{16}$ The differences in health care organization and oversight, insurance coverage and population density are important to consider in interpreting our findings.

Third, our work should be considered in the context of growing recognition of the importance of international comparative research. ${ }^{47}$ Hip fracture is an ideal condition for international comparative research because diagnosis is relatively simple and admission to hospital is standard practice in the developed world. ${ }^{54}$ Thus, unlike with conditions such as pneumonia, joint arthroplasty or even myocardial infarction, for which patients may (or may not) seek medical care, ${ }^{26,55-57}$ patients with hip fracture tend to be comparable across geographic regions, and selection effects are minimal. ${ }^{11,58}$ Although geographic variations in care are well described within countries, ${ }^{59,60}$ cross-border research is much more limited. ${ }^{61,62}$ Challenges include data access, privacy regulations and differences in coding practices. ${ }^{7}$ However, international comparisons offer unprecedented opportunities to compare the impact of large-scale policy interventions (financing, incentives, organization) in ways that single-country studies simply cannot. ${ }^{63}$

Finally, a few more minor findings merit brief mention. It is important to note the lower hospital readmission rate we observed in Manitoba. The US health care system has long been characterized by high readmission rates. ${ }^{64,65}$ Our results suggest that hospital readmissions in the US could be reduced. ${ }^{66}$ Our finding of higher use of nonoperative management in New York was surprising. Our prior research using national US Medicare data from 1991-2008 showed that about $5 \%$ of all patients with hip fracture were treated without surgery; ${ }^{28}$ our finding that $8.3 \%$ of femoral neck fractures in New York were managed without surgery warrants confirmation. ${ }^{67}$ Our finding of a significantly higher hip fracture rate in Manitoba than in New York (22.7 v. 16.7 per 10000 adults per year) is also surprising. Although there have been studies of hip fracture rates within single countries, ${ }^{2,68}$ there have been few studies directly comparing hip fracture rates between countries with the use of populationlevel data. The EuroHOPE (European Health Care Outcomes, Performance and Efficiency) study group found that annual hip fracture rates among adults aged 50 or more varied from 31 per 10000 in Finland to 138 per 10000 in Italy, with 5 additional European countries somewhere in between, ${ }^{10}$ although methodological differences preclude direct comparison with our work. We suspect that the higher rate of hip fracture in Manitoba could be explained by factors including long winters (with risk for falls), limited sunlight with resultant vitamin D deficiency and a population that is largely of European descent. ${ }^{69,70}$

\section{Limitations}

Our study has several limitations that warrant mention. First, it was limited to 1 Canadian province and 1 US state, and the findings must be generalized with care. Moreover, the relatively small number of patients and hospitals in Manitoba 
may have increased the risk of failing to detect a ManitobaNew York difference when such a difference truly exists (i.e., type 2 error). Second, because of inherent limitations in the New York SID data, we were forced to limit our analysis to hospital data alone in both New York and Manitoba to ensure parity in data between jurisdictions. We also were unable to differentiate discharge to rehabilitation from discharge to long-term care, and this is an important distinction. Third, we lacked access to detailed clinical variables such as frailty, laboratory values and postfracture functional status. Fourth, our study is based on data from 2011-2013 and may not entirely reflect practice today.

\section{Conclusion}

Poor short-term outcomes for patients with hip fracture in Manitoba that were documented in the 1980s seem to have improved. Patients in Manitoba who experience hip fracture now appear to fare as well as their New York counterparts with respect to short-term outcomes.

\section{References}

1. Leslie WD, O'Donnell S, Jean S, et al. Trends in hip fracture rates in Canada. 7AMA 2009;302:883-9.

2. Brauer CA, Coca-Perraillon M, Cutler DM, et al. Incidence and mortality of hip fractures in the United States. FAMA 2009;302:1573-9.

3. Mundi S, Pindiprolu B, Simunovic N, et al. Similar mortality rates in hip fracture patients over the past 31 years. Acta Orthop 2014;85:54-9.

4. Miller BJ, Cai X, Cram P. Mortality rates are similar after hip fractures for rural and urban patients. Clin Orthop Relat Res 2012;470:1763-70.

5. Morin S, Lix LM, Azimaee M, et al. Mortality rates after incident nontraumatic fractures in older men and women. Osteoporos Int 2011;22:2439-48.

6. Morin S, Lix LM, Azimaee M, et al. Institutionalization following incident non-traumatic fractures in community-dwelling men and women. Osteoporos Int 2012;23:2381-6.

7. Papanicolas I, Jha AK. Challenges in international comparison of health care systems. 7AMA 2017;318:515-6.

8. Roos LL, Walld RK, Romano PS, et al. Short-term mortality after repair of hip fracture. Do Manitoba elderly do worse? Med Care 1996;34:310-26.

9. Roos LL, Fisher ES, Sharp SM, et al. Postsurgical mortality in Manitoba and New England. 7AMA 1990;263:2453-8.

10. Medin E, Goude F, Melberg HO, et al. European regional differences in allcause mortality and length of stay for patients with hip fracture. Health Econ 2015;24(Suppl 2):53-64.

11. Ho V, Hamilton BH, Roos LL. Multiple approaches to assessing the effects of delays for hip fracture patients in the United States and Canada. Health Serv Res 2000;34:1499-518.

12. Kreindler SA, Siragusa L, Bohm E, et al. Regional consolidation of orthopedic surgery: impacts on hip fracture surgery access and outcomes. Can 7 Surg 2017;60:349-54.

13. Bohm E, Loucks L, Wittmeier K, et al. Reduced time to surgery improves mortality and length of stay following hip fracture: results from an intervention study in a Canadian health authority. Can 7 Surg 2015;58:257-63.

14. Benchmarks for treatment and wait time in Canada: hip fracture repair. Ottawa: Canadian Institute for Health Information. Available: http://waittimes. cihi.ca/All/fracture?level=default (accessed 2018 Dec. 5).

15. Cram P, Yan L, Bohm E, et al. Trends in operative and nonoperative hip fracture management 1990-2014: a longitudinal analysis of Manitoba administrative data. F Am Geriatr Soc 2017;65:27-34.

16. Gunja MZ, Collins SR, Doty MM, et al. Insurance coverage, access to care, and medical debt since the ACA: a look at California, Florida, New York, and Texas. Issue Brief (Commonw Fund) 2017;7:1-12.

17. Dy CJ, Lane JM, Pan TJ, et al. Racial and socioeconomic disparities in hip fracture care. 7 Bone foint Surg Am 2016;98:858-65.

18. Roos LL, Fisher ES, Brazauskas R, et al. Health and surgical outcomes in Canada and the United States. Health Aff (Millwood) 1992;11:56-72.

19. Population and dwelling count highlight tables, 2016 census. Ottawa: Statistics Canada; modified 2018 Feb. 8. Available: https://www12.statcan.gc.ca/census -recensement/2016/dp-pd/hlt-fst/pd-pl/Table.cfm?Lang=Eng $\&$ T $=101 \& S=50$ $\& \mathrm{O}=\mathrm{A}$ (accessed 2018 Nov. 26).

20. QuickFacts: New York. Washington: United States Census Bureau. Available: https://www.census.gov/quickfacts/fact/table/ny/PST045217 (accessed 2019 Jan. 24).
21. Smith M, Lix LM, Azimaee M, et al. Assessing the quality of administrative data for research: a framework from the Manitoba Centre for Health Policy. $f$ Am Med Inform Assoc 2017 Sept. 1 [Epub ahead of print]. doi: 10.1093/jamia/ ocx078.

22. Quan H, Sundararajan V, Halfon P, et al. Coding algorithms for defining comorbidities in ICD-9-CM and ICD-10 administrative data. Med Care 2005, 43:1130-9.

23. Healthcare Cost and Utilization Project (HCUP). HCUP databases: overview of the State Inpatient Databases (SID). Rockville (MD): Agency for Healthcare Research and Quality; 2018; modified 2018 July 24. Available: www.hcup-us. ahrq.gov/sidoverview.jsp (accessed 2018 Nov. 26)

24. White C. Cutting medicare hospital prices leads to a spillover reduction in hospital discharges for the nonelderly. Health Serv Res 2014;49:1578-95.

25. Glance LG, Osler TM, Mukamel DB, et al. Impact of the present-onadmission indicator on hospital quality measurement: experience with the Agency for Healthcare Research and Quality (AHRQ) Inpatient Quality Indicators. Med Care 2008;46:112-9.

26. Cram P, Landon BE, Matelski J, et al. Hip and knee arthroplasty utilization and outcomes in the United States and Canada: an analysis of New York and Ontario administrative data. Arthritis Rheumatol 2018;70:547-54.

27. Elixhauser A, Steiner C, Harris DR, et al. Comorbidity measures for use with administrative data. Med Care 1998;36:8-27.

28. Miller BJ, Lu X, Cram P. The trends in treatment of femoral neck fractures in the Medicare population from 1991 to 2008. F Bone foint Surg Am 2013;95: e132.

29. Curtin LR, Klein RJ. Direct standardization (age-adjusted death rates). Healthy People 2000 Stat Notes 1995;(6):1-10.

30. Vaughan-Sarrazin MS, Lu X, Cram P. The impact of paradoxical comorbidities on risk-adjusted mortality of Medicare beneficiaries with cardiovascular disease. Medicare Medicaid Res Rev 2011;1:E1-17.

31. Silverman E, Skinner J. Medicare upcoding and hospital ownership. 7 Health Econ 2004;23:369-89.

32. Landon BE, Mechanic RE. The paradox of coding - policy concerns raised by risk-based provider contracts. NEngl F Med 2017;377:1211-3.

33. Luft HS, Bunker JP, Enthoven AC. Should operations be regionalized? The empirical relation between surgical volume and mortality. N Engl 7 Med 1979; 301:1364-9.

34. Grumbach K, Anderson GM, Luft HS, et al. Regionalization of cardiac surgery in the United States and Canada. Geographic access, choice, and outcomes. 7AMA 1995;274:1282-8.

35. Hughes RG, Garnick DW, Luft HS, et al. Hospital volume and patient outcomes: the case of hip fracture patients. Med Care 1988;26:1057-67.

36. Browne JA, Pietrobon R, Olson SA. Hip fracture outcomes: Does surgeon or hospital volume really matter? 7 Trauma 2009;66:809-14.

37. Kristensen PK, Thillemann TM, Johnsen SP. Is bigger always better? A nationwide study of hip fracture unit volume, 30-day mortality, quality of inhospital care, and length of hospital stay. Med Care 2014;52:1023-9.

38. Hamilton BH, Ho V. Does practice make perfect? Examining the relationship between hospital surgical volume and outcomes for hip fracture patients in Quebec. Med Care 1998;36:892-903.

39. Pincus D, Ravi B, Wasserstein D, et al. Association between wait time and 30-day mortality in adults undergoing hip fracture surgery. $7 A M A$ 2017;318: 1994-2003.

40. Hinde YR, Pennington R, Nott ML. Time to surgery for hip fracture patients in a rural orthopaedic referral hospital. Aust 7 Rural Health 2017;25:42-4.

41. Sutherland JM, Crump RT. Alternative level of care: Canada's hospital beds, the evidence and options. Healthc Policy 2013;9:26-34.

42. Hart A, Bergeron SG, Epure L, et al. Comparison of US and Canadian perioperative outcomes and hospital efficiency after total hip and knee arthroplasty. 7AMA Surg 2015;150:990-8.

43. Rahme E, Kahn SR, Dasgupta K, et al. Short-term mortality associated with failure to receive home care after hemiarthroplasty. CMA7 2010;182:1421-6.

44. Ivers N, Brown AD, Detsky AS. Lessons from the Canadian experience with single-payer health insurance: just comfortable enough with the status quo. 7AMA Intern Med 2018;178:1250-5.

45. Cram P, Dhalla I, Kwan JL. Trade-offs: pros and cons of being a doctor and patient in Canada. 7 Gen Intern Med 2017;32:563-5.

46. Naylor CD. Canada as single-payer exemplar for universal health care in the United States: a borderline option. 7AMA 2018;319:17-8.

47. Papanicolas I, Woskie LR, Jha AK. Health care spending in the United States and other high-income countries. FAMA 2018;319:1024-39.

48. How Canada compares: results from The Commonwealth Fund 2015 International Health Policy Survey of primary care physicians. Ottawa: Canadian Institute for Health Information; 2016.

49. Squires D, Anderson CUS. Health care from a global perspective: spending, use of services, prices, and health in 13 countries. Issue Brief (Commonw Fund) 2015;15:1-15.

50. Schneider EC, Squires D. From last to first - Could the U.S. health care system become the best in the world? N Engl 7 Med 2017;377:901-4.

51. Davis K, Stremikis K, Squires D, et al. Mirror mirror on the wall: bow the US bealth care system performs internationally. New York: The Commonwealth Fund; 2014. 
52. Ethnic origins, 2006 counts, for Canada, provinces and territories - $20 \%$ sample data. Ottawa: Statistics Canada; modified 2010 Oct. 6.

53. Manitoba. Wikipedia; edited 2018 Dec. 24. Available: https://en.wikipedia.org/ wiki/Manitoba (accessed 2018 Dec. 7).

54. Bhandari M, Swiontkowski M. Management of acute hip fracture. $N$ Engl $f$ Med 2017;377:2053-62.

55. de Groot MC, Klungel OH, Leufkens HG, et al. Sources of heterogeneity in case-control studies on associations between statins, ACE-inhibitors, and proton pump inhibitors and risk of pneumonia. Eur f Epidemiol 2014;29:767-75.

56. Bagai A, Alexander KP, Berger JS, et al. Use of troponin assay 99th percentile as the decision level for myocardial infarction diagnosis. Am Heart 7 2017;190: $135-9$.

57. Hickman PE, Koerbin G, Potter JM, et al. Statistical considerations for determining high-sensitivity cardiac troponin reference intervals. Clin Biochem 2017; 50:502-5.

58. Birkmeyer JD, Gust C, Baser O, et al. Medicare payments for common inpatient procedures: implications for episode-based payment bundling. Health Serv Res 2010;45:1783-95.

59. Welch WP, Miller ME, Welch HG, et al. Geographic variation in expenditures for physicians' services in the United States. N Engl f Med 1993;328: 621-7.

60. Fisher ES, Wennberg DE, Stukel TA, et al. The implications of regional variations in Medicare spending. Part 1: the content, quality, and accessibility of care. Ann Intern Med 2003;138:273-87.

61. Herrett E, Shah AD, Boggon R, et al. Completeness and diagnostic validity of recording acute myocardial infarction events in primary care, hospital care, disease registry, and national mortality records: cohort study. BM7 2013;346:f2350.

62. Chung SC, Gedeborg R, Nicholas O, et al. Acute myocardial infarction: a comparison of short-term survival in national outcome registries in Sweden and the UK. Lancet 2014;383:1305-12.

63. Baicker K, Chandra A. Challenges in understanding differences in health care spending between the United States and other high-income countries. $7 A M A$ 2018;319:986-7.

64. Kociol RD, Lopes RD, Clare R, et al. International variation in and factors associated with hospital readmission after myocardial infarction. FAMA 2012; 307:66-74.

65. Joynt KE, Orav EJ, Jha AK. Thirty-day readmission rates for Medicare beneficiaries by race and site of care. 7AMA 2011;305:675-81.

66. McGarry BE, Blankley AA, Li Y. The impact of the Medicare Hospital Readmission Reduction Program in New York State. Med Care 2016;54:162-71.

67. Neuman MD, Silber JH, Magaziner JS, et al. Survival and functional outcomes after hip fracture among nursing home residents. FAMA Intern Med 2014;174: 1273-80.

68. Lefaivre KA, Levy AR, Sobolev B, et al. Changes in first hip fracture rates in British Columbia Canada, 1990-2004. Osteoporos Int 2011;22:2817-27.
69. Odén A, Kanis JA, McCloskey EV, et al. The effect of latitude on the risk and seasonal variation in hip fracture in Sweden. 7 Bone Miner Res 2014;29:2217-23.

70. Solbakken SM, Magnus JH, Meyer HE, et al. Impact of comorbidity, age, and gender on seasonal variation in hip fracture incidence. A NOREPOS study. Arch Osteoporos 2014;9:191.

Affiliations: North American Observatory on Health Systems and Policies (Cram), Institute for Health Policy, Management and Evaluation, University of Toronto; Departments of Medicine (Cram) and Surgery (Gandhi), University of Toronto; Division of General Internal Medicine and Geriatrics (Cram), Sinai Health System and University Health Network, Toronto, Ont.; Departments of Community Health Sciences (Lix, Bohm, Yan, Roos), Surgery (Bohm) and Medicine (Leslie), University of Manitoba, Winnipeg, Man.; Biostatistics Research Unit (Matelski) and Arthritis Program (Gandhi), University Health Network, Toronto, Ont.; Department of Health Care Policy (Landon), Harvard Medical School; Division of General Medicine and Primary Care (Landon), Beth Israel Deaconess Medical Center, Boston, Mass.

Contributors: Peter Cram, William Leslie, Lisa Lix and Bruce Landon conceived and designed the study. All of the authors contributed to data acquisition, analysis and interpretation, and drafting the manuscript and critically revising it for important intellectual content, gave final approval of the version to be published and agreed to be accountable for all aspects of the work.

Funding: Peter Cram is supported by a K24 AR062133 award from the National Institute of Arthritis and Musculoskeletal and Skin Diseases, National Institutes of Health.

Acknowledgements: The authors acknowledge the Manitoba Centre for Health Policy for use of data contained in the Population Health Research Data Repository under project HIPC 2008/2009-16. The data were derived from data provided by Manitoba Health.

Disclaimer: The results and conclusions are those of the authors, and no official endorsement by the Manitoba Centre for Health Policy, Manitoba Health or other data providers is intended or should be inferred.

Supplemental information: For reviewer comments and the original submission of this manuscript, please see www.cmajopen.ca/content/7/1/ E55/suppl/DC1. 